\title{
Timing and Frequency of Antenatal Care Utilization in Slums: Assessing Determinants over time
}

\author{
Kanyiva Muindi', Blessing Mberu', Patricia Elung'ata ${ }^{2}$ and Maharouf Oyolola ${ }^{3}$ \\ ${ }^{1}$ Urbanization and Wellbeing Program, African Population and Health Research Center \\ P.O. Box 10787-00100, Nairobi \\ ${ }^{2}$ McGill University,45 Rue Sherbrooke O, \\ Montréal, QC H3A 0G4, Canada \\ ${ }^{3}$ Nairobi Kenya. \\ kmuindi@aphrc.org
}

\begin{abstract}
Timely and adequate antenatal care (ANC) attendance is important in maternal health. This paper examined the factors associated with ANC utilization in Nairobi slums in 2000 and 2012. Data come from two cross sectional surveys in the slums in Nairobi city. We fitted multinomial and logistic regression models to assess respectively, factors associated with timing of the first ANC visit and the frequency of ANC visits. In both years, parity, mother's ethnic group and educational attainment were significantly associated with timing of first ANC visit. Frequency of visits was significantly associated with mother's educational attainment, parity, pregnancy wantedness and place of residence. We conclude that for optimal ANC utilization, there is need to improve women's educational outcomes and address cultural barriers to utilization.
\end{abstract}

\section{Résumé}

L'utilisation appropriée et en temps opportun des services de soins prénatals (ANC) est importante pour la santé maternelle. Cette étude a examiné les déterminants de la fréquentation des services de soins prénatals en 2000 et 2012 dans les bidonvilles de Nairobi. Les données proviennent de deux enquêtes transversales conduits dans les bidonvilles de la ville de Nairobi. Nous avons construits des modèles de régression logistique multinomiale et binomiale pour évaluer, respectivement, les facteurs associés au calendrier de la première visite prénatale et la fréquence des visites prénatales. Pour les deux périodes, la parité, le groupe ethnique de la mère et le niveau d'éducation étaient associés au stade de la grossesse calendrier de la première visite prénatale. La fréquence des visites était associée au niveau d'éducation de la mère, à la parité, au désir de la grossesse et au lieu de résidence. L'utilisation optimale des soins prénatals est associée au groupe ethnique de la mère, au niveau d'éducation et à la parité. Nous concluons que pour une utilisation optimale des soins prénatals, il est nécessaire d'améliorer le niveau d'éducation des femmes et d'éliminer les obstacles culturels à l'utilisation de ces soins. Une attention particulière devrait être donnée aux facteurs conduisant à des parités élevées et ceux empéchant les femmes à parité élevée d'utiliser les services de soins prénatals.

\section{Introduction}

Despite recent estimates indicating a general decline in global maternal mortality ratio (MMR) (United Nations, 20II, Hogan et al., 20I0), it still remains high in Kenya, at 488 deaths per 100,000 live births (Kenya National Bureau of Statistics (KNBS) and ICF Macro, 2010). There exist disparities between different segments of the population in the country with the MMR in the slums of Nairobi being estimated at 706 per 100,000 live births between 2003 and 2005 (Ziraba et al., 2009). This is attributable to among other factors, the lack of appropriate maternal health services in these communities (Ziraba et al., 2009). There is generally an absence of public health facilities within the slums, leading to reliance on for-profit health facilities with implications for access to services due to high costs. Most of these facilities have been found to lack skilled personnel and necessary equipment to deal with obstetric emergencies (Essendi et al., 2010, Fotso et al., 2008). In addition, transport costs to health facilities and poverty are important barriers to maternal health care utilization in the slums, contributing to the high MMR in these settings 
(Izugbara and Ngilangwa 2010). Slums have high MMR despite evidence indicating that antenatal care (ANC) attendance is near universal (lzugbara et al., 2009, Rossier et al., 20।4).

The leading causes of maternal mortality in the country which include hemorrhage, sepsis, hypertension and obstructed labor (Interparliamentary Union et al., ND), are preventable through timely and adequate antenatal care as well as efficient referral systems for cases that require advanced medical interventions. Other indirect causes of maternal mortality include malaria, anemia, tuberculosis, and HIV/AIDS, conditions that can be identified and addressed during antenatal care visits. Appropriate antenatal care is an important component of maternal health care as it provides the opportunity for health care personnel to identify and address any health concerns of the mother including potential obstetric complications Timely initiation of antenatal care is therefore important as it provides an opportunity for timely management of complications and appropriate follow up of high risk pregnancies. Lack of or inadequate antenatal care has been identified as one of the risk factors for poor maternal and newborn outcomes globally and in Kenya in particular (United Nations Population Fund (UNFPA), 20II, Partridge et al., 2012, Magadi et al., 200I).

The Kenya government's guidelines on ANC attendance recommends at least four visits for pregnancies assessed to progress normally, with the visits spread across the trimesters, and the first visit occuring in the first trimester (Inter-parliamentary Union et al., ND). This is in line with the WHO focused ANC package (Villar et al., 200I). During the ANC visit, pregnant mothers receive a range of services including iron/folic supplementation, immunization against maternal and neonatal tetanus, monitoring of blood pressure, maternal weight and protein in urine. Further, there is testing for and management of various infections such as HIV and Syphilis. Thus in order to fully benefit from the full range of ANC services, the timing of the initial visit to the ANC provider and the frequency of visits are important in determining the timeliness of interventions that might be needed in case the pregnancy is not progressing well or if there are complications. Available evidence shows that the rate of ANC utilization in Kenya is high (Kenya National Bureau of Statistics (KNBS) and ICF Macro, 20I0). However, appropriate timing of ANC remains a challenge with most women in the slums and nationally initiating the first visit later than what the existing guidelines recommend (Kenya National Bureau of Statistics (KNBS) and ICF Macro, 20I0, Ochako et al., 20I I).
Late initiation of ANC has implications for the timing of subsequent visits and the frequency of visits throughout the pregnancy. There are also implications for the timeliness of some of the services outlined in the ANC package. For instance failure to make the first visit during the first trimester would mean a missed opportunity for folic acid supplementation with implications for the health of the fetus and in later life. The effects of low folic acid levels in pregnancy include low birth weight of the fetus (Molloy et al., 2008 ) which can lead to other negative outcomes in adulthood including poor educational and labour market outcomes (Conley et al., 2003, Black et al., 2007). Further, folic acid has been shown to protect against neural tube defects, thus, lack of adequate and timely supplementation might increase the risk of experiencing such or other forms of defects with negative consequences later in life (Molloy et al., 2008 ). Other services such as screening for HIV and Syphilis are also conducted early in the pregnancy and it is therefore of utmost importance that women initiate ANC early. In the slums of Nairobi where HIV prevalence has been found to be particularly high (Madise et al., 20I2), it is especially important that mothers initiate ANC early to ensure timely testing and intervention with antiretroviral therapy if necessary, for the benefit of the mother's health and subsequently that of the baby (WHO, 20I0).

This paper assesses the factors associated with the timing and frequency of ANC among women in the slums of Nairobi. It was informed by the fact that previous research on timing and frequency of ANC focused on specific sub-groups of child-bearing women such as adolescents (Ochako et al., 20l I); women with unwanted fertility (Gage, 1998) or women of specific communities (Magadi et al., 2000, Eijk et al., 2006). In addition most of the studies controlled for place of residence without distinguishing between slum and non-slum urban areas.

\section{Data and methods}

Data used in this paper are from the 2000 and 2012 Nairobi Cross-sectional Slum Surveys which were conducted among a representative sample of slum residents. Further details about the surveys can be found in (African Population and Health Research Center (APHRC), 2002; 2014). This paper is based on information on mother's utilization of antenatal care services for the last birth that occurred in the three years prior to the survey. There were a total of 1716 and 1305 births in 2012 and 2000 respectively. Respondents who indicated that they attended antenatal clinics were asked about the trimester in which they initiated these visits and also about the 
number of times they went to the ANC service provider during the pregnancy. Early ANC in this made in the second or third trimester. Two definitions of ANC frequency were used: a relaxed definition, with mothers making fewer than four visits being considered as having less than optimal ANC visits; and a stricter definition with those who made four or more visits but the first visit was not within the first trimester being considered as having made less than optimal visits.

To assess the factors associated with the timing of the first ANC visit, we fitted a multinomial regression model with the base outcome being those women initiating ANC during the first trimester, which is the ideal timing according to the Kenyan ANC schedule. We controlled for various factors including educational attainment, household wealth status, marital status, parity, religion, pregnancy wantedness, division of residence, and ethnicity of the mother. Educational attainment was measured by the highest class of formal schooling completed. Pregnancy wantedness was derived from the question on whether the woman wanted to become pregnant at the time she conceived the last child, later or not all. A pregnancy was wanted if the woman indicated that she wanted to become pregnant then and unwanted if otherwise. We, however, take cognizance of the fact that mothers are likely to change their views once a baby is born and report that the pregnancy was wanted, hence the indicator might not fully capture wantedness of a pregnancy due to such rationalization. Division of residence was used to determine whether there were spatial differences in ANC timing which could be due to availability of these services within reach as opposed to utilization being influenced by individual choices alone. The ethnic background of the mother was used as an indicator of cultural differences that could influence timing of first ANC visit. We estimated separate models for 2000 and 2012 to determine which paper was defined as making the first visit in the first trimester while late ANC was defined as first visit factors were consistently associated with ANC utilization over time.

Frequency of ANC visits was derived from the question asked of women reporting to have attended an antenatal clinic on the number of times they went for ANC services during the index pregnancy. We assessed the factors associated with the frequency of ANC visits by fitting two logistic regression models for those making at least four ANC visits. In the unrestricted model, we considered all women who reported making at least four ANC visits regardless of when the first visit was made as having attained the requisite visits, while in the restricted model, we considered those making at least four visits with the first visit being made within the first trimester. We controlled for similar characteristics as in the multinomial models.

\section{Results}

Sample description

In the 2012 sample, women were mostly aged between 25 and 29 years (37.2\%); were in a marital union (either married or cohabiting, $81.1 \%$ ) and had completed primary level of education (42.8\%). On the other hand, women in the 2000 survey were mostly aged $20-24$ years (35.4\%) and majority were in a marital union (81.5\%). Most of the women in the two surveys lived households falling in the least poor segment of the population according to the assetbased household wealth index $(42 \%$ in 2012 and $41 \%$ in 2000). Majority of the women (64\% in 2012 and $69 \%$ in 2000) had made at least four ANC visits during the index pregnancy, while the first ANC visit was made during the second trimester by $65.6 \%$ of the women in 2012 and $68.7 \%$ in 2000 (see Table I). When we restrict the four visits to women who made their initial visit during the first trimester, the proportion making at least four ANC visits is $16.8 \%$ in 2012 and $10.7 \%$ in 2000. 
Table I: Distribution of sample by select demographic characteristics, 2000 \& 2012.

\begin{tabular}{lll} 
& 2000 & 2012 \\
\hline & Percent & Percent \\
\hline Mother's Age & 11.1 & 7.0 \\
Below 20 years & 35.4 & 30.4 \\
20-24 years & 29.4 & 37.2 \\
$25-29$ years & 13.2 & 15.9 \\
$30-34$ years & 11.0 & 9.6 \\
35+ years & & \\
Mother's education & 20.7 & 9.9 \\
None/incomplete primary & 46.9 & 42.8 \\
Complete primary & 32.4 & 47.3 \\
Secondary+ & & \\
Marital status & 81.5 & 81.1 \\
In union & 18.5 & 18.9 \\
Not in union & & \\
Household wealth index & 24.4 & 24.4 \\
Poorest & 34.6 & 33.6 \\
Middle & 41.0 & 42.0 \\
Least poor & & \\
ANC frequency & 31.0 & 36.0 \\
<4 times & 69.0 & 64.0 \\
At least 4 times & & 100 \\
Timing of first ANC visit & 11.0 & 21.1 \\
Ist trimester & 68.7 & 65.6 \\
2nd trimester & 20.3 & 100 \\
3rd trimester & 1,305 & \\
Total & & \\
N & & \\
\hline
\end{tabular}

\section{Timing of first ANC visit}

Results indicate that in 2012, maternal ethnic group, educational attainment, parity and Division of residence as well as the wantedness of the pregnancy, religion and household wealth were significantly associated with the timing of the first ANC visit (see Table 2). Compared with mothers from Kikuyu ethnic group, Kisii mothers were more than twice as likely to initiate ANC in the second trimester while Luo mothers were significantly less likely to initiate ANC in the second or third trimester if they did not do so in the first trimester. In addition, compared with mothers with complete primary education, those with secondary or higher levels of education were significantly less likely to initiate ANC in the second trimester if they did not do so in the first trimester. Though not statistically significant, we find that women with no or incomplete primary education were more likely to initiate ANC later in pregnancy. Estimates for household wealth and marital status were not statistically significant. Women who had given birth to three or more children were more likely to start ANC visits later in pregnancy than those with only one child. Among women who reported that the pregnancy was unwanted (totally unwanted or mistimed), we find that there were increased odds of late ANC initiation although this was significant at the 10\% level. Place of residence as represented by the administrative Division was only significant for ANC initiation during the second trimester for women living in Kasarani and Pumwani Divisions compared with mothers living in Dagoretti Division. Women who reported their religious affiliation as Catholic were significantly less likely to initiate ANC in the second trimester compared to those reporting to be Protestants.

Results from the 2000 survey show that timing of the first ANC visit was significantly influenced by maternal ethnic group, educational attainment, 
wantedness of the pregnancy and parity. Women from the Luhya women and those from other smaller ethnic groups were significantly less likely to initiate ANC in the third trimester if they did not do so in the first trimester compared to women from Kikuyu ethnic group. Compared with women with complete primary education, those with incomplete primary or no formal education and those with secondary or higher levels of education were significantly less likely to initiate ANC late. In addition, women reporting that the pregnancy was unwanted were more likely to initiate ANC late while those who had given birth to two or more children were more likely to initiate ANC in the second and last trimesters.

Table 2: Relative risk ratios from multinomial logit models examining factors associated with timing of first ANC visit in 2000 and 2012

2000

2012

2nd trimester 3rd trimester 2nd trimester 3rd trimester

Parity-CEB $^{\wedge}$ (Ref: 1 birth)

2 births

$1.77 * *$

0.95

0.9

$3+$ births

$1.64 * *$

$2.67 * * *$

$1.46^{* *}$

$2.11 * * *$

Mother's education (Ref: complete primary)

None/incomplete primary

$0.59 * *$

0.81

1.07

1.03

Secondary+

0.75

$0.58^{* *}$

$0.74 * *$

$0.73 *$

Ethnic group (Ref: Kikuyu)

$\begin{array}{lcccc}\text { Kamba } & 0.77 & 0.68 & 1.13 & 0.65 \\ \text { Kisii } & 1.3 & 0.53 & 2.67 * * * & 1.63 \\ \text { Luhya } & 0.61^{*} & 0.44^{* *} & 0.82 & 0.7 \\ \text { Luo } & 0.82 & 0.63 & 0.64 * * & 0.50^{* *} \\ \text { Other } & 0.36^{* *} & 0.30^{* *} & 0.79 & 0.53\end{array}$

Wantedness of pregnancy (Ref: unwanted)

Wanted

1.12

$1.67 * *$

1.08

$1.43 *$

Place of residence (Ref: Dagoretti)

Kibera

0.78

0.6

1.08

0.68

Embakasi

1.17

1.18

1.18

Makadara

2.85

3.54

1.05

1.28

Central

0.66

$0.44 *$

1.29

1.52

Kasarani

0.94

0.83

1.89 ***

1.17

Pumwani

0.6

0.4

$2.23 * *$

$2.56^{*}$

Westlands

0.76

0.62

0.99

1.72

Religion (Ref: Protestant)

Catholic

Islam/other

1.53

1.6

0.61

0.49

Note significance: * 10\%; ** 5\%; *** |\%; ^ CEB = Children Ever Born

\section{Frequency of ANC visits}

From the unrestricted model, (Table 3) results indicate that in 2012, parity, mother's educational attainment, household wealth, wantedness of the pregnancy and place of residence were significantly associated with the frequency of ANC visits. Compared with women with complete primary education, those who had not received formal education and those who had incomplete primary education were less likely to make at least four ANC visits. Multi-parous women in the order of three and above were less likely to make the four visits compared with uniparous women while those reporting that the pregnancy was unwanted were less likely to make the four visits. Women from the poorest and moderately poor households were significantly less likely to make the four visits compared with those from least poor households. 
With respect to place of residence, there were significant differences in the frequency of ANC visits between Embakasi and Dagoretti Divisions. In 2000, pregnancy wantedness, household wealth and place of residence were important drivers of ANC frequency. As in 2012, women reporting that the pregnancy was unwanted were less likely to make the minimum ANC visits while those from moderately poor households were less likely to make the four visits. Women from Westlands Division were significantly more likely to make at least four ANC visits while those from Kibera and Kasarani were significantly less likely to make the visits compared to their counterparts from Dagoretti.

Results from the model restricting the outcome to women who made at least four visits in addition to initiating ANC in the first trimester showed that parity, mother's educational attainment, mother's ethnic group, pregnancy wantedness and the place of residence were significantly associated with the frequency of visits in 2012. The estimates for household wealth and maternal age were not statistically significant. Results for 2000 indicate that only parity and maternal ethnic group were significantly associated with making the minimum ANC visits, while education was marginally significant. Pregnancy wantedness and household wealth status were significantly associated with the frequency of ANC visits in the unrestricted but not in the restricted model for 2000. In addition, although parity was not significantly associated with the frequency of ANC visits in the unrestricted model for 2000 , the association was statistically significant in the restricted model for both years.

Table 3: Odds ratios from logistic regression models examining for factors associated with ANC frequency in 2000 \& 2012

\begin{tabular}{|c|c|c|c|c|}
\hline & \multicolumn{2}{|c|}{ Unrestricted model } & \multicolumn{2}{|c|}{ Restricted model } \\
\hline & 2000 & 2012 & 2000 & 2012 \\
\hline & OR & OR & OR & OR \\
\hline \multicolumn{5}{|l|}{ Parity-CEB^ (Ref: I birth) } \\
\hline 2 births & 0.97 & 1.04 & 0.73 & 1.00 \\
\hline $3+$ births & 0.95 & $0.76 * *$ & $0.56 * *$ & $0.50 * * *$ \\
\hline \multicolumn{5}{|c|}{ Mother's education (Ref: complete primary) } \\
\hline None/incomplete primary & $0.75^{*}$ & $0.70 * *$ & 1.51 & 0.84 \\
\hline Secondary + & $1.29 *$ & 1.17 & $1.47^{*}$ & $1.34 * *$ \\
\hline \multicolumn{5}{|l|}{ Ethnic group (Ref: Kikuyu) } \\
\hline Kamba & 0.97 & 1.25 & 1.31 & 1.05 \\
\hline Kisii & 0.96 & 0.92 & 0.86 & $0.39 * *$ \\
\hline Luhya & 0.90 & 0.87 & $1.62 *$ & 1.30 \\
\hline Luo & 0.76 & 1.03 & 1.24 & $1.82 * *$ \\
\hline Other & 0.90 & 1.17 & $2.87^{* *}$ & 1.54 \\
\hline \multicolumn{5}{|c|}{ Wantedness of pregnancy (Ref: wanted) } \\
\hline Unwanted & $0.75 * *$ & $0.66^{* * * *}$ & 0.84 & $0.64 * * *$ \\
\hline \multicolumn{5}{|c|}{ Household wealth index (Ref: least poor) } \\
\hline Poorest & $0.73^{*}$ & $0.72 * *$ & 0.71 & 1.01 \\
\hline Moderate & $0.73 * *$ & $0.75^{* * *}$ & 1.16 & 0.80 \\
\hline \multicolumn{5}{|c|}{ Place of residence (Ref: Dagoretti) } \\
\hline Kibera & $0.6 I^{* * *}$ & 0.96 & 1.40 & 0.97 \\
\hline Embakasi & $0.65^{*}$ & $0.54 * * *$ & 0.89 & $0.68 *$ \\
\hline Makadara & 0.64 & 0.85 & 0.34 & 0.94 \\
\hline Central & 0.93 & 0.81 & 1.78 & $0.56 *$ \\
\hline Kasarani & $0.55^{* *}$ & $0.67^{* *}$ & 1.10 & $0.57^{* *}$ \\
\hline Pumwani & $\mid .31$ & 1.01 & 1.92 & $0.53^{*}$ \\
\hline Westlands & $2.5 I^{* * *}$ & 0.95 & 1.36 & 0.85 \\
\hline Religion (ref: Other Christ & & & & \\
\hline
\end{tabular}




\begin{tabular}{lll|lc|} 
Catholic & 1.01 & 0.99 & 0.96 & 1.20 \\
Islam/other & 1.54 & 1.43 & 0.65 & $1.90 * *$ \\
\hline
\end{tabular}

Note: significance: * 10\%; ** 5\%; *** 1\%

Unrestricted model: At least four ANC visits with first visit at any time in pregnancy

Restricted model: At least four ANC visits frequency with first visit in first trimester

$\wedge \mathrm{CEB}=$ Children Ever Born

\section{Discussion and Conclusion}

This paper assessed the factors associated with the timing of the first ANC visit and the frequency of these visits among women living in Nairobi slums in 2000 and 2012. We find differences in the factors associated with both outcomes. Younger mothers, as indicated by lower parity since this was highly correlated with age, were significantly less likely to make at least four ANC visits. This could be influenced by the high numbers of unmarried women in younger age groups who might shy away from ANC providers for fear of hostile treatment as is evident from other studies in the country and elsewhere (Finlayson and Downe, 2013, Atuyambe L et al., 2009, Izugbara et al., 2009). It might also be that being unmarried confers an economic disadvantage on these women, most of who were unemployed and could be facing financial constraints that limit their ability to pay for ANC visits in the mostly for-profit private health facilities in the slums. Indeed women's employment has been found to influence ANC utilization (Bibha et al., 2008). Ethnic background was significantly associated with timing and frequency of ANC in both surveys. However, its association with frequency of ANC visits was only statistically significant for those making the first visit in the first trimester. Ethnic background measures unobserved cultural values and practices that might influence health behavior. For example, some traditions bar pregnant women from discussing their pregnancy with other people during the first trimester for fear of witchcraft befalling the pregnant mother leading to loss of the fetus (Pell et al., 2013, Finlayson and Downe, 2013). Such beliefs might bar women from these ethnic groups from making ANC visits early in pregnancy.

Mother's level of education was protective as expected against late initiation of ANC visits and making fewer than four ANC visits during the pregnancy. Higher levels of education equip mothers with information that they use later in their lives. For example, they are able to identify the signs of a pregnancy early and initiate ANC promptly (Gross et al., 20/2). It is also possible that higher education confers an economic advantage to these women who are more likely to be employed and are therefore able to meet the costs associated with ANC visits. Education has been shown to influence ANC frequency and timing in other studies (Elo, T. I.,
1992, Magadi et al., 2000). There were, however, some unexpected findings regarding the association between the level of education and ANC utilization in 2000. In particular, women with no formal or incomplete primary education were significantly less likely to initiate ANC in the second trimester if they did not do so in the first trimester compared to their counterparts with secondary or higher levels of education. This finding points to sustained disadvantage among these women if they do not initiate ANC visits in the first trimester.

Lower household economic status was negatively associated with the frequency of ANC visits which might point to constraints in the allocation of resources for ANC-related costs among poorer households. Although ANC services are free in all public health facilities, slums lack such facilities and therefore women have to pay for the services at private health facilities. Further, poor households might lack amenities that allow the diffusion of information regarding pre-natal care compared with those from least poor households, placing women in those households at a disadvantage. Similar findings have been reported elsewhere (Ochako et al., 20I I).

Multiparous women $(3+$ births) were more likely to initiate ANC late in pregnancy and were less likely to make at least four ANC visits in both surveys. This finding could be attributed to prior experience with pregnancy whereby the women might not see the need to seek ANC early especially if earlier pregnancies did not have any complications unlike uniparous women who might be uncertain about the pregnancy's progress and are therefore more likely to seek ANC early and make more visits. A systematic review of the literature found that higher parity was significantly associated with less ANC utilization (Bibha et al., 2008). In addition, multiparous women are likely older and there exists evidence of these women being ill-treated by service providers who embarrass them for being pregnant in their later years (Izugbara et al., 2009). This can result in some women keeping off ANC altogether or delaying the visits. Reported wantedness of the pregnancy mattered in the frequency of ANC visits in both surveys while it was significantly associated with ANC initiation for 2000 only. The finding could reflect women's desires to have uncomplicated deliveries and ultimately healthy babies in cases of 
planned pregnancies. Evidence exists of women delaying or not making any ANC visits at all if the pregnancy was unwanted (Pell et al., 20I3).

We conclude that in the slums of Nairobi, the timing of the first ANC visit and attaining optimal ANC is dependent on mother's educational attainment, parity and her ethnic background. It is therefore important for programs aiming to motivate women to initiate ANC early and to get optimal ANC, to address cultural beliefs and age/parity effects that constrain women from making early and optimal ANC visits. There should be a push towards bringing free ANC services to slums similar to what has been done for child immunization. This will ensure that all women regardless of their education and economic situation access this important service. There is also need to address the underlying reasons associated with less than optimal antenatal care among women of higher parity.

\section{References}

African Population and Health Research Center 2002. Population and Health Dynamics in Nairobi's Informal Settlements. Nairobi: APHRC.

African Population and Health Research Center (APHRC) 20I4. Population and Health Dynamics in Nairobi's Informal Settlements: Report of the Nairobi Cross-sectional Slums Survey (NCSS) 2012. Nairobi: APHRC.

Atuyambe L, Mirembe F, Annika J, Kirumira E. K. \& Faxelid, E. 2009. Seeking safety and empathy: adolescent health seeking behavior during pregnancy and early motherhood in central Uganda.

Bibha, S., Van-Teijlingen, E. R., Porter, M. \& Simkhada, P. 2008. Factors affecting the untilization of antenatal care in developing countries: systematic review of the literature. Journal of Advanced Nursing, 61, 244-260.

Black, S. E., Devereux, P. J. \& Salvanes, K. G. 2007. From the Cradle to the Labor Market? The Effect of Birth Weight on Adult Outcomes. The Quarterly Journal of Economics.

Conley, D., Strully, K. W. \& Bennett, N. G. 2003. Is Biology Destiny? Birth Weight, Infant Mortality and Educational Achievement. The Starting Gate: Birth Weight and Life Chances. Berkeley: University of California Press.

Eijk, A. M. V., Bles, H. M., Odhiambo, F., Ayisi, J. G., Blokland, I. E., Rosen, D. H., Adazu, K., Slutsker, L. \& Lindblade, K. A. 2006. Use of antenatal services and delivery care among women in rural western Kenya: a community based survey. Reproductive Health, 3.
Essendi, H., Mills, S. \& Fotso, J.-C. 20I0. Barriers to Formal Emergency Obstetric

Care Services' Utilization. Journal of Urban Health, 88, 356-69.

Finlayson, K. \& Downe, S. 2013. Why Do Women Not Use Antenatal Services in Low- and MiddleIncome Countries? A Meta-Synthesis of Qualitative Studies. PLoS Med, 10.

Fotso, J. C., Ezeh, A., Madise, N., Ziraba, A. \& Ogollah, R. 2008. What does access to maternal care mean among the urban poor? Factors associated with use of appropriate maternal health services in the slum settlements of Nairobi, Kenya. Maternal \& Child Health Journal, 10.1007/s 10995-008-0326-4.

Gage, A. J. 1998. Premarital Childbearing, Unwanted Fertility and Maternity Care in Kenya and Namibia. Population Studies, 52, 21-34.

Gross, K., Alba, S., Glass, T. R., Schellenberg, J. A. \& Obrist, B. 2012. Timing of antenatal care for adolescent and adult pregnant women in southeastern Tanzania. BMC Pregnancy and Childbirth 12.

Hogan, M. C., Foreman, K. J., Naghavi, M., Ahn, S. Y., Wang, M., Makela, S. M., Lopez, A. D., Lozano, R. \& Murray, C. J. L. 2010. Maternal mortality for I8I countries, 1980-2008: a systematic analysis of progress towards Millennium Development Goal 5. The Lancet, 375, 1609-1623.

Inter-Parliamentary Union, The Partnership for Maternal Newborn and Child Health \& Parliament of Kenya ND. Maternal and Child Health: Kenya. World Health Organization.

Elo, I. T., 1992. Utilization of maternal health-care services in Peru: the role of women's education. Health Transition Review, 2.

Izugbara, C. \& Ngilangwa, D. 20I0. Women, poverty and adverse maternal outcomes in Nairobi, Kenya. BMC Women's Health, 10, 33.

Izugbara, C. O., Ezeh, A. C. \& Fotso, J. C. 2009. The persistence and challenges of homebirths: perspectives of traditional birth attendants in urban Kenya. Health Policy and Planning, 24, 3645.

Kenya National Bureau of Statistics (KNBS) \& Icf Macro 2010. Kenya Demographic and Health Survey 2008-09. Calverton, Maryland: KNBS and ICF Macro.

Magadi, M., Diamond, I. \& Madise, N. 200I. Analysis of factors associated with maternal mortality in Kenyan hospitals. Journal of Biosocial Science, 33, 375-389.

Magadi, M. A., Madise, N. J. \& Rodrigues, R. N. 2000. Frequency and timing of antenatal care in Kenya: explaining the variations between women of 
different communities. Social Science \& Medicine 5I, $55 I-6 I$.

Molloy, A. M., Kirke, P. N., Brody, L. C., Scott, J. M. \& Mills, J. L. 2008 Effects of folate and vitamin BI2 deficiencies during pregnancy on fetal, infant, and child development. Food Nutr Bull 29, SIOI-II; discussion SI I 2-5.

Madise, J. N., Ziraba, A. K., Inungu, J., Khamadi, S. A., Ezeh, A., Zulu, E. M., Kebaso, J, Okoth, V. \& Mwau, M. 2012. Are slum dwellers at heightened risk of HIV infection than other urban residents? Evidence from population-based HIV prevalence surveys in Kenya. Health Place, 18, II44-II 52.

Ochako, R., Fotso, J.-C., Ikamari, L. \& Khasakhala, A. 2011. Utilization of maternal health services among young women in Kenya: Insights from the Kenya Demographic and Health Survey, 2003. BMC Pregnancy and Childbirth, II.

Partridge, S., Balayla, J., Holcroft, C. A. \& Abenhaim, H. A. 2012. Inadequate Prenatal Care Utilization and Risks of Infant Mortality and Poor Birth Outcome: A Retrospective Analysis of 28,729,765 U.S. Deliveries over 8 Years. Am J Perinatol, 29, 787-794.

Pell, C., Menaca, A., Were, F., Afrah, N. A., Chatio, S., Manda-Taylor, L., Hamel, M. J., Hodgson, A., Tagbor, H., Kalilani, L., Ouma, P. \& Pool, R. 2013. Factors Affecting Antenatal Care Attendance:
Results from Qualitative Studies in Ghana, Kenya and Malawi. PLOS ONE 8.

Rossier, C., Muindi, K., A. Soura, B. Mberu, B. Lankoande, C. Kabiru \& Millogo, R. 2014. Maternal health care utilization in Nairobi and Ouagadougou: Evidence from HDSS. Global Health Action 7.

United Nations 201 I. The Millennium Development Goals Report 201 I. New York: United Nations.

United Nations Population Fund (UNFPA) 20II. The State of the World's Midwifery 20I I. UNFPA.

Villar, J., Ba'aqeel, H., Piaggio, G., Lumbiganon, P., Belizán, J. M., Farnot, U., Al-Mazrou, Y., Carroli, G., Pinol, A., Donner, A., Langer, A., Nigenda, G., Mugford, M., Fox-Rushby, J., Hutton, G., Bergsjø, P., Bakketeig, L. \& Berendes, H. 200I. WHO antenatal care randomised trial for the evaluation of a new model of routine antenatal care. The Lancet, 357, I55 I-I564.

WHO. 2010. New guidance on prevention of mother-to-child transmission of HIV and infant feeding in the context of HIV [Online]. Available: www.who.int/hiv/pub/mtct/PMTCTfactsheet/en/ [Accessed 5th February 20I5].

Ziraba, A., Madise, N., Mills, S., Kyobutungi, C. \& Ezeh, A. 2009. Maternal mortality in the informal settlements of Nairobi city: what do we know? Reprod 